\title{
SIMPÓSIO
}

\section{Efeitos da apreciação cambial na poupança interna: analise teórica e evidências para o Brasil}

\author{
Paulo Gala*
}

RESUMO - Esta nota tem por objetivo apresentar perspectivas teóricas que exploram possíveis canais macro dos efeitos da apreciação cambial e algumas evidências empíricas para o caso brasileiro. O trabalho discute os efeitos da apreciação (depreciação) cambial nos níveis de renda, consumo e poupança interna e analisa o caso brasileiro recente.

Palavras-chave: Nível do câmbio real. Poupança. Investimento.

\section{INTRODUÇÃO}

A moeda brasileira tem se valorizado intensamente nos últimos dois anos. Nesse contexto, voltam a surgir argumentos favoráveis à apreciação do câmbio real. Alguns economistas argumentam que um Real apreciado seria favorável à aquisição de máquinas e equipamentos no exterior, estimulando o investimento agregado, ou ainda que o câmbio apreciado facilitaria a aquisição de tecnologias que não possuímos no mercado mundial. Ambos os argumentos, entretanto, parecem não descrever bem o que se observou durante a intensa apreciação cambial brasileira ao longo dos anos 90: baixo nível de investimento agregado e baixo dinamismo tecnológico da indústria brasileira, especialmente se comparados ao que ocorreu no leste da Ásia.

O efeito mais forte da apreciação cambial nas cadeias produtivas de bens comercializáveis, tanto agrícolas quanto de bens industriais, se faz sentir principalmente nas margens de lucro. Para um dado nível de preços em dólares de produtos comercializáveis, a apreciação cambial representa uma queda de preços de venda e margens de lucro em reais em toda a cadeia que trabalha com preços internacionais, especialmente nos setores que não têm poder de mercado. A redução de preços de máquinas e equipamentos importados decorrente da apreciação cambial está longe de compensar a redução nos lucros. Que baixos, não estimulam o investimento. Os aumentos de importação de bens de capital observados na balança comercial são principalmente direcionados para os setores de bens não comercializáveis e para a

\footnotetext{
* Doutor e professor de Economia pela FGV/SP. Endereço Eletrônico: pgala@uol.com.br.
} 
substituição da produção de máquinas e equipamentos domésticos, o que por si só pode reduzir nossa capacidade de inovação e melhora tecnológica em setores de ponta.

Dentro dessa temática, esta nota tem por objetivo apresentar perspectivas teóricas que exploram possíveis canais macro dos efeitos da apreciação cambial e algumas evidências empíricas para o caso brasileiro. Além dessa breve introdução, o trabalho está dividido em 3 seções. As seções 2 e 3 apresentam perspectivas teóricas sobre os efeitos da apreciação (depreciação) cambial nos níveis de renda, consumo e poupança interna e analisam o caso brasileiro recente. A última seção traz algumas breves conclusões.

\section{EFEITOS DO CÂMBIO REAL NA POUPANÇA INTERNA}

Uma apreciação cambial reduz o preço de venda dos bens comercializáveis e, tudo o mais constante (ou seja, salários nominais, preços externos e produtividade) reduz a margem de lucro desse setor. No entanto, a apreciação cambial pode aumentar os lucros do setor de bens não comercializáveis que opera com insumos importados. No caso do setor de bens comercializáveis que opera com insumos importados, uma apreciação cambial sempre reduzirá a margem de lucro, para uma dada escala de produção, pois a queda no preço de venda tende a ser maior do que a queda de um componente parcial do custo. $O$ argumento de que o câmbio apreciado é favorável ao investimento agregado por baratear o preço de máquinas e equipamentos, pode ser entendido aqui como uma situação em que o preço reduzido de insumo aumenta a margem de lucro para um setor não comercializável. O mesmo argumento não se aplica para bens comercializáveis.

Uma apreciação cambial reduz, portanto, o lucro do setor de bens comercializáveis, mantém inalterado o lucro do setor de não comercializáveis e aumenta o lucro do setor de não comercializáveis que trabalha com insumos importados. O efeito final sobre a lucratividade da economia, para uma dada escala de produção, dependerá do tamanho relativo de cada setor. Se o setor de bens comercializáveis for maior do que o setor de não comercializáveis que trabalha com insumos importados, necessariamente uma apreciação cambial reduzirá os lucros da economia. Quanto maior o componente não comercializável do custo de produção de comercializáveis, maior será esse efeito.

Resta ver como ficam as outras variáveis da economia como decorrência da apreciação (depreciação) cambial. O nível geral de preços deve cair (subir), pois nada mais é do que um 
composto de preço de comercializáveis e não comercializáveis. O salário real deve aumentar (cair), pois é uma relação entre salário nominal e nível de preços. O câmbio real deve se apreciar (depreciar) na medida em que o câmbio nominal cai (sobe) mais do que o aumento do nível geral de preços que depende, em parte, dos preços de não comercializáveis. E, por fim, se assumirmos que o setor de comercializáveis é maior do que o de não comercializáveis com insumos importados, o lucro geral da economia deve cair. Ou seja, para dados níveis de produtividade e salário nominal, uma apreciação cambial resulta numa redução nas margens de lucro do sistema e aumentos do salário real. Resta ver como as dinâmicas de determinação de renda, investimento e poupança são afetadas por essa queda de lucros no curto e no longo prazo.

Levando-se em consideração a hipótese de que os trabalhadores consomem toda sua renda, aumentos dos salários reais significarão reduções da poupança interna e aumentos de consumo. Como conseqüência, a demanda agregada poderá cair ou aumentar, dependendo dos efeitos da queda das margens de lucro na função investimento. Se o investimento for pouco elástico a variações nas margens de lucro, quedas de salário real terão efeitos recessivos, pois a queda do consumo não será compensada por um aumento de investimento dos empresários. Essa é a clássica tese do subconsumo, onde reduções de salário real reduzem o consumo e demanda agregada. Se os investimentos forem altamente sensíveis à margem de lucro, teremos então o efeito oposto. Reduções do salário real aumentarão os lucros que por sua vez aumentarão a demanda agregada e a utilização de capacidade instalada. A economia entrará numa trajetória do tipo investment-led growth.

Em economia aberta, uma desvalorização real do câmbio reduzirá o salário real e aumentará a margem de lucro dos empresários. Haverá aumento de investimento, exportações e nível de renda contanto que as funções sejam suficientemente elásticas. O aumento dos lucros contribuirá para o aumento da poupança interna. Nos casos de sobrevalorização cambial haverá elevação artificial dos salários que contribuirá para o aumento do consumo e redução da poupança interna.

\section{EVOLUÇÃO DA POUPANÇA INTERNA NO BRASIL}

Numa economia com contas públicas relativamente equilibradas, a poupança interna privada mais a externa é igual ao investimento. Seguindo a argumentação acima, sabemos que tanto importações e exportações quanto a poupança interna dependerão da taxa de câmbio. As trajetórias de poupança interna e externa dependem do câmbio, já que este afeta todas as 
variáveis acima elencadas. Com funções suficientemente elásticas, um câmbio real mais depreciado poderá aumentar o nível de renda via aumento de exportações, reduzir o nível de consumo, aumentar a poupança interna, reduzir a poupança externa e aumentar o nível de investimento. Teríamos, portanto, o clássico caso asiático onde o crescimento puxado por investimentos e exportações resulta em superávits em conta corrente.

Podemos imaginar também outros tipos de trajetória. Um câmbio sobrevalorizado pode aumentar o nível de renda via aumento do consumo e dependendo das elasticidades, via aumento do investimento. Nesse tipo de trajetória, o crescimento será necessariamente acompanhado de aumento de poupança externa. A situação de déficit em conta-corrente é compatível com crescimento puxado pelo consumo e eventualmente puxado pelos investimentos. Teríamos aqui o padrão mais tradicional observado na América Latina com crescimento e déficits em contas correntes.

Alguns autores têm argumentado que o modelo asiático não seria implementável no Brasil ou América Latina devido ao baixo nível de poupança privada. Invertendo a causalidade entre déficit em conta corrente e poupança, os autores argumentam que a baixa propensão individual a consumir dos asiáticos seria responsável pelos altos níveis de poupança interna e superávits em conta corrente. A discussão acima mostra que é possível endogenizar o consumo como função do salário real que por sua vez depende do câmbio real. Assim o segredo para o alto nível de poupança dos asiáticos estaria, segundo essa argumentação, nos reduzidos salários reais, dado um nível de produtividade. A poupança interna depende do nível da taxa de câmbio.

No caso latino-americano, as sucessivas crises cambiais dos últimos anos seriam explicadas pelo elevado nível de consumo e excessiva utilização de poupança externa. Tentativas de crescimento puxado pelo consumo a partir de câmbios reais sobrevalorizados e salários artificialmente elevados resultariam numa "insuficiência" de poupança interna e déficit em conta corrente. O problema latino-americano da "insuficiência de poupança" estaria na sobrevalorização cambial.

O gráfico abaixo mostra a evolução da poupança interna brasileira desde os anos 2000. Percebe-se claramente um forte aumento de 4 pontos percentuais ocorrido a partir de 2003. Esse movimento está ligado, segundo nosso argumento, ao forte ajuste de preços relativos, ocorrido a partir da desvalorização do câmbio real em 2002. 
GRÁFICO 1 - EVOLUÇÃO DA POUPANÇA INTERNA NO BRASIL - 2000- 20007

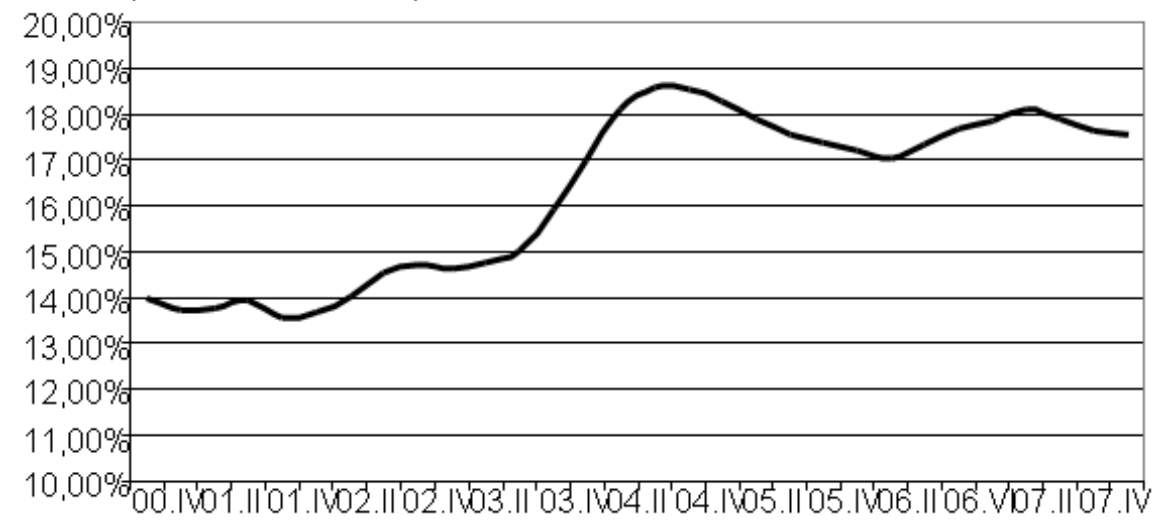

FONTE: Elaboração própria com dados do Sistema de Contas Nacionais IBGE.

Os painéis abaixo mostram uma sobreposição da evolução recente de nossa taxa câmbio real e poupança interna. O segundo painel mostra uma relação interessante entre o nível da taxa de poupança e o nível do câmbio real defasado em 3 períodos. São evidências preliminares, obviamente, e dependem de estudos mais aprofundados, mas de todo modo, apontam para uma relação relevante entre câmbio e poupança interna.

GRÁFICO 2 - CÂMBIO REAL E POUPANÇA INTERNA - 1995 - 2007

Câmbio real e poupança interna

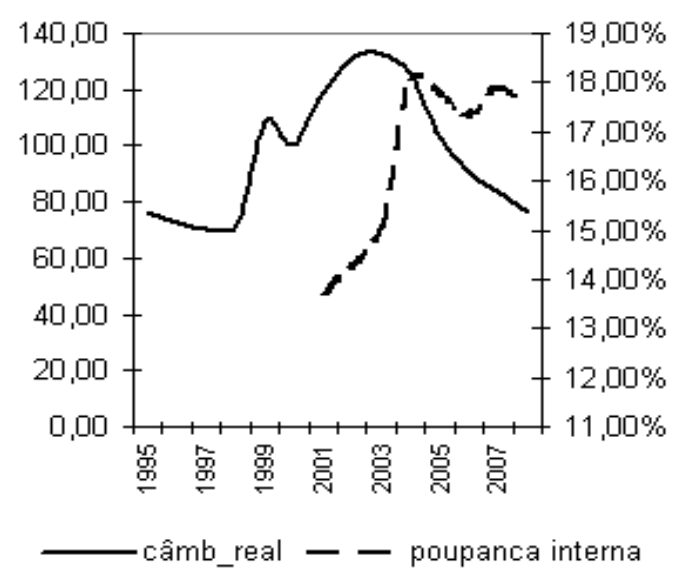

Cambio real defasado em 3 periodos e poupanca interna

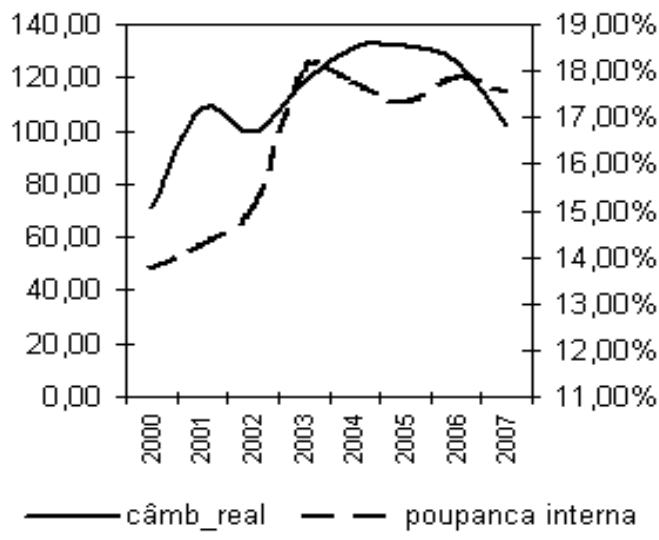

FONTE: Elaboração própria com dados do Sistema de Contas Nacionais IBGE.

Para concluir, vale notar que toda a discussão acima é feita a partir de determinados níveis de produtividade. A elevação do salário real sem contrapartida de aumentos de produtividade é problemática, pois acaba por colocar a economia numa trajetória insustentável que termina numa crise de balanço de pagamentos. Por outro lado, numa situação de câmbio competitivo há um aumento de lucratividade dos investimentos que tende a aumentar o nível de 
produtividade da economia no longo prazo, permitindo aumentos de salários reais de forma equilibrada.

\section{CONCLUSÕES}

Os argumentos apresentados nas seções anteriores procuraram discutir os impactos do nível do câmbio real nos salários reais, taxas de lucro, investimento agregado, poupança externa e interna. As primeiras seções trataram dos efeitos de curto prazo do nível do câmbio real na lucratividade das empresas e nos níveis de poupança interna. Em casos de sobrevalorização excessiva, a redução das margens de lucro nos setores de produção de bens comercializáveis e aumento do consumo, resultarão em uma queda da poupança interna.

Para os setores produtores de bens não comercializáveis ou de comercializáveis maquiladores, a apreciação cambial poderá significar um aumento de margens na medida em que reduzirá preços de insumos importados sem reduzir preços de venda. O efeito líquido final da apreciação do câmbio no investimento agregado será, portanto, ambíguo, dependendo do nível de utilização da capacidade instalada, do tamanho do setor de comercializáveis e da proporção de insumos importados na indústria como um todo. É importante notar, entretanto, que mesmo que o investimento agregado aumente, pode haver uma especialização setorial perversa da economia no sentido de restrições do balanço de pagamentos e capacidade de geração de divisas. Se grande parte do investimento estiver concentrada no setor produtor de bens não comercializáveis, haverá grande probabilidade de restrição de divisas para o crescimento no longo prazo.

Em relação ao caráter regressivo de políticas cambiais que estimulem o aumento de competitividade da moeda, é importante notar que políticas compensatórias devem ser usadas no curto prazo para compensar a queda relativa do salário real. Por outro lado, vale destacar que tentativas de aumento do salário real pela via da sobrevalorização cambial têm, em geral, se mostrado bastante problemáticas. Os inúmeros casos de populismo cambial e crise na América Latina recentemente são testemunhas disso. A via por excelência de aumento sustentado do salário real passa pela redução do desemprego e incorporação dos trabalhadores nos setores dinâmicos da economia mundial, como bem mostraram as experiências asiáticas de sucesso. Uma política de câmbio competitivo tem exatamente esse objetivo. Ao promover a competitividade das indústrias domésticas contribui para a mudança estrutural da economia que é, em última análise, o que causa o desenvolvimento econômico. 


\section{REFERÊNCIAS}

BRESSER-PEREIRA, L.,C. e GALA, P. Foreign savings, insufficiency of demand and low growth, Journal of Post Keynesian Economics, vol. 30, n.3, p.315-334, 2008.

BRESSER-PEREIRA, L.,C. (2006). Exchange rate, fix, float or manage it? Preface to Mathias Vernengo, (ed.) Financial Integration or Dollarization: No Panacea. Cheltenham: Edward Elgar.

BHADURI, A., and MARGLIN, S., A. (1990). Unemployment and the real wages: the economic basis for contesting political ideologies. Cambridge Journal of Economics, 14, December.

BARBOSA-FILHO, N., (2006). Exchange rates, growth and inflation. In: ANNUAL CONFERENCE ON DEVELOPMENT AND CHANGE ACDC, 2., Campos do Jordão, Brazil, November 2006.

Frenkel, r., (2004). Real exchange rate and employment in Argentina, Brazil, Chile and Mexico. Cedes, Buenos Aires, paper presented to the G24.

FRENKEL, Roberto, and TAYLOR, Lance (2006). Real exchange rate, monetary policy and employment. Desa Working paper n.19, United Nations, New York.

GALA, P., e LIBÂNIO, G.,. Exchange rate policies, patterns of specialization and economic development: theory and evidence in developing countries. In: ANNUAL CONFERENCE ON DEVELOPMENT AND CHANGE ACDC, 3., 2007, Cidade do Cabo, África do Sul, Dezembro 2007.

GALA, P., e LUCINDA, C. Exchange rate misalignment and growth: old and new econometric evidence. In: ENCONTRO NACIONAL DE ECONOMIA, ANPEC,34.,2006, Salvador.

Rodrik, D., (2007). Real Exchange Rate and Economic Growth: Theory and Evidence. John F. Kennedy School of Government, Harvard University, Draft, July.

ROS, Jaime (2002). Trade specialization and economic growth. in J. M. Fanelli and R. Medhora (eds.), Finance and Competitiveness in Developing Countries. London: Routledge. 
SILVA, G., J., C., OREIRO, J., L., NAKABASHI, L., e LEMOS, B., P., (2007). A macroeconomia do crescimento puxado pela demanda agregada: teoria e aplicações ao caso brasileiro. In: ENCONTRO NACIONAL DE ECONOMIA, ANPEC, 35., 2007, Recife.

Sistema de Contas Nacionais. Brasília: IBGE. Disponível em: http://www.ibge.gov.br/home/ estatistica/indicadores/pib/defaultcnt.shtm. Acesso em: 10/09/2008.

WILLIAMSON, J, (2003). Exchange rate policy and development. Presented in Initiative for Policy Dialogue Task Force on Macroeconomics, New York. 